\title{
3D Whole Brain Vessel Wall Imaging of Primary Angiitis of the Central Nervous System: 5 Cases and Literature Review
}

\section{Yao Yu}

Jilin University https://orcid.org/0000-0001-8235-0212

\section{Hong-Wei Zhou}

Jilin University First Hospital

\section{Zhen-Ni Guo}

Jilin University First Hospital

Hang Jin

Jilin University First Hospital https://orcid.org/0000-0003-0300-5918

\section{Fu-Liang Zhang}

Jilin University First Hospital

\section{Peng-Peng Niu}

Jilin University First Hospital

Yun Luo

Jilin University First Hospital

\section{Chao Wang}

Jilin University First Hospital

\section{Ming-Chao Shi}

Jilin University First Hospital

Jia Liu

Shenzhen Institutes of Advanced Technology Chinese Academy of Sciences

\section{Hai-Qiang Qin}

Beijing Tiantan Hospital

Yi Yang ( $\sim$ doctoryangyi@163.com )

\section{Case report}

Keywords: vessel wall imaging, primary angiitis of the central nervous system

Posted Date: April 23rd, 2019

DOI: https://doi.org/10.21203/rs.2.9296/v1

License: (1) This work is licensed under a Creative Commons Attribution 4.0 International License. Read Full License 


\section{Abstract}

Background Primary angiitis of the central nervous system is an uncommon single-organ vasculitis that is still poorly understood, and its diagnosis can be quite challenging. Traditional vascular imaging techniques could only show the abnormality of vessel lumen, while primary angiitis of the central nervous system as well as atherosclerosis or other mimics could show similar patterns, like tapering of the vessel lumen or multiple stenosis. Vessel wall magnetic resonance imaging can directly visualize the abnormality of the vessel wall, therefore has become a valuable approach for vasculopathy evaluation. However, 2D vessel wall magnetic resonance imaging can only be restricted to one fixed angle for one scanning process, while vasculitis tends to involve multiple vessels. With the development of 3D isotropic vessel wall imaging sequence, it can achieve a thorough view of the whole brain vasculature in shorter time and apply reconstruction in any angle. Reasonably, 3D isotropic vessel wall imaging could help with the diagnosis, evaluation and follow-up of primary angiitis of the central nervous system more effectively. Case presentation We present five cases of primary angiitis of the central nervous system that underwent 3D isotropic vessel wall imaging, along with follow-up. The diagnosis of primary angiitis of the central nervous system was made by classic diagnosis criteria. The youngest patient was 21 years old, while the oldest one was 49 years old. As for disease onset, one patient presented with headache, while other four patients presented with ischemic stroke. Both anterior circulation and posterior circulation of the five patients were involved, regardless of the responsible vessel. They were given steroids, immunosuppressor or parahormone for management. On follow-up vessel imaging, one patient displayed gradual vessel occlusion in 12 months, one patient showed partial resolution, other three patients presented with vasculopathy persistence. Conclusions 3D isotropic vessel wall imaging could evaluate the specific responsible vessel as well as the whole brain vasculature in one-time scan, providing detailed information in detection, diagnosis, evaluation and follow-up. Moreover, primary angiitis of the central nervous system tend to be multi-vessel involving, so the 3D isotropic vessel wall imaging could be more applicable.

\section{Background}

Primary angiitis of the central nervous system (PACNS) is an uncommon vasculopathy that may lead to various neurological complications(1). The diagnosis of PACNS can be quite challenging due to the diverse clinical features. Brain biopsy is still the gold standard for diagnosis, but due to the invasive feature of the procedure, it has its own limits, especially for intracranial vessels. Traditional angiographies, such as computed tomography angiography (CTA), time-of-flight magnetic resonance angiography (TOFMRA), and digital subtraction angiography (DSA), are difficult to differentiate PACNS from other mimics owing to the similar luminal findings, such as tapering of the vessel lumen and multiple stenosis(2).

Vessel wall magnetic resonance imaging (VW-MRI) is an emerging approach that can directly visualize the vessel wall as well as the lumen; therefore, it can help clinicians differentiate various vasculopathies(3). In studies, vasculitis usually showed smooth, homogeneous, concentric arterial wall thickening and enhancement in VW-MRI, while atherosclerosis plaque usually displayed an eccentric and heterogeneous pattern $(4,5)$. However, the scanning process of vasculopathy by 2D VW-MRI can only be restricted to one fixed angle for one time scanning process, while vasculitis tends to involve multiple vessels. Also, intracranial vessels can be quite tortuous, so it is difficult to interpret the images precisely through one fixed plane(6). Besides, some lesions of the vasculature may be asymptomatic or non-stenotic on TOF-MRA, while 2D VW-MRI sequences are generally applied on stenotic segments, so the nonstenotic or asymptomatic lesions might be overlooked. 3D isotropic VW-MRI can reduce total scan time, providing more flexibility in radiograph reading, supporting image reconstruction from all angles. Furthermore, it can achieve a whole view of the head and neck vasculature in about 6 minutes, providing thorough information for the whole brain vasculature evaluation. Since PACNS tend to be multi-vessel involving, 3D isotropic VW-MRI could be more appropriate.

In this article, we present 5 cases that were ultimately diagnosed of PACNS, with particular imaging characteristics on 3D isotropic VWMRI and follow-up, which could provide some information on the application of 3D isotropic VW-MRI in PACNS.

\section{Case Presentation}

We retrospectively reviewed the imaging database of 3D isotropic V W-MRI from April 2015 to March 2017 in the First Hospital of Jilin University. Five PACNS cases with thorough 3D isotropic VW-MRI were included. All the diagnosis were made according to the diagnostic criteria proposed by Calabrese et al(7) independently of the VW-MRI findings. Four of these five patients underwent 3D isotropic VW-MRI on the Achieva 3-Tesla scanner (Philips Healthcare, Eindhoven, The Netherlands), 1 on 3-Tesla Trio Tim magnetic resonance imaging (MRI) Scanner (Siemens Healthcare, Erlangen, Germany). The sequence brand and parameters for Siemens Scanner are as follows: 3D T1-weighted Sampling Perfection with Application optimized Contrast using different angle Evolutions-oblique 
coronal plane acquisition; variable refocusing flip angle; repetition time, $550 \mathrm{~ms}$; echo time, $18 \mathrm{~ms}$; field of view $=210 \mathrm{~mm} \times 210 \mathrm{~mm}$; acquired voxel size $=0.8 \mathrm{~mm} \times 0.8 \mathrm{~mm} \times 0.8 \mathrm{~mm}$; scanning time: $4 \mathrm{~m} 46 \mathrm{~s}$; before and after intravenous gadolinium $(0.1-0.2 \mathrm{mmol} / \mathrm{kg})$. 2D T1 VW-MRI: repetition time, $1060 \mathrm{~ms}$; echo time, $25 \mathrm{~ms}$; FA: $180^{\circ}$; slice thickness: $2.0 \mathrm{~mm}$; field of view: $150 \mathrm{~mm} \times 150 \mathrm{~mm}$; NSE:4; number of averages: 2 ; echo train length: 7; scanning time: $3 \mathrm{~m} 14 \mathrm{~s}$. The sequence brand and parameters for Philips Scanner are as follows: 3D T1-weighted volumetric isotropic turbo spin echo acquisition-oblique coronal plane acquisition; variable refocusing flip angle; repetition time, $350 \mathrm{~ms}$; echo time, $19 \mathrm{~ms}$; field of view $=210 \mathrm{~mm} \times 210 \mathrm{~mm}$; acquired voxel size $=0.8 \mathrm{~mm} \times 0.8 \mathrm{~mm} \times 0.8 \mathrm{~mm}$; scanning time: $4 \mathrm{~m} 46 \mathrm{~s}$; before and after intravenous gadolinium $(0.1-0.2 \mathrm{mmol} / \mathrm{Kg})$. A 12-channel head coil was used for the above sequences. The enhancement intensity was scaled by an established assessment forum(8), in which grade 0 indicated no enhancement, grade 1 indicated the enhancement intensity was less than that of pituitary infundibulum, and grade 2 indicated intensity equal or greater compared with pituitary infundibulum. Further, the pattern of enhancement was assessed as heterogeneous or homogeneous.

2.1 Case 1: A 21-year-old male worker presented with paroxysmal right-sided hemiplegia and aphasia, and each time recovered in 10 minutes. He denied any traditional cerebrovascular risk factors. No abnormalities in cranial nerve examination. No paresthesia, dyskinesia or pyramidal sign was identified. Diffusion weighted imaging (DWI) displayed acute ischemic infarction in the left middle cerebral artery (MCA) territory, whereas magnetic resonance angiography (MRA) showed diffuse stenosis of the right internal carotid artery (ICA) and the right MCA (Fig 1A). Laboratory tests for rheumatologic disorders, autoimmune diseases, and infectious causes of vasculopathy were all negative. 3D isotropic VW-MRI showed uniform thickening of the right ICA vessel wall with contrast enhancement (Fig 1B). Intravenous dexamethasone $15 \mathrm{mg}$ was prescribed for 9 days. After discharge, steroid therapy was adjusted to dexamethasone $60 \mathrm{mg}$ orally and then reduced to $10 \mathrm{mg}$ per 14 days. The patient was followed up at 2, 3, 6, and 12 months, and no acute ischemic infarction was noted. For the 3-month imaging follow-up, the stenosis of the right ICA had not reverted (Fig 1D), while the enhancement intensity declined (Figure 1E). But it was worth noting that the vessel wall of the left vertebral artery had been thickening (Fig 1F) compared with baseline imaging (Fig 1C), and occluded on 6 months (Fig $1 \mathrm{G}, \mathrm{I}$ ), indicating progression of vasculitis. He was given cyclophosphamide from 6-months follow-up, but the 12-month imaging follow-up (Fig 1J, L) showed persistent occlusion of the left vertebral artery.

2.2 Case 2: A 26-year-old male farmer presented with recurrent stroke in the past year. No traditional cerebrovascular risk factors were noted. Neurological examination revealed blepharoptosis and abducent pupil on the left side, along with speech disorder and bilateral electropositive cone bundle pathology. Routine MRI confirmed both acute and chronic ischemic infarction within the posterior circulation territory. MRA revealed severe stenosis of the left MCA and poor visualization of the posterior circulation. (Fig 2A). Laboratory indicators for rheumatologic disorders, autoimmune diseases, and infectious causes of vasculopathy were all negative. 3D isotropic VW-MRI showed uniform vessel wall thickening with contrast enhancement of the right vertebral artery, the basilar artery, and the left posterior cerebral artery (Fig 2B-E). The patient was ultimately diagnosed of PACNS and was prescribed steroids for management. On the 1-year follow-up, the vasculopathy was still persistent (Fig 2F-I).

2.3 Case 3: A 35-year-old male farmer presented with paroxysmal and progressive headache in the previous 2 weeks. No abnormalities in cranial nerve examination. No paresthesia, dyskinesia or pyramidal sign was identified. The patient denied any traditional cerebrovascular risk factors other than smoking, with no history of drug abuse. DWI confirmed acute ischemic infarction in the right centrum semiovale. MRA revealed occlusion of the right ICA, and the right MCA was not visualized (Add Fig 1A). Laboratory tests for rheumatologic disorders, autoimmune diseases, and infectious causes of vasculopathy were all negative. 3D isotropic VW-MRI showed uniform thickening of the vessel wall of the right ICA with contrast enhancement (Add Fig 1B-E). The patient was ultimately diagnosed of PACNS after thorough evaluation and was prescribed steroids for management. On 3 months, he still reported paroxysmal headache but did not complete a follow-up in neuroimaging.

2.4 Case 4: A 49-year-old male worker presented with episodic headache for 2 years and worsening for 4 days. He was a longtime smoker with no relevant medical history. No abnormalities in cranial nerve examination. No paresthesia, dyskinesia or pyramidal sign was identified. Routine MRI showed no obvious abnormalities, while MRA revealed several vessel stenosis (Add Fig 2A). For laboratory tests, erythrocyte sedimentation rate was $22 \mathrm{~mm} / 1 \mathrm{~h}$ (normal range $0-15 \mathrm{~mm} / 1 \mathrm{~h}$ ), and hypersensitive C-reactive protein was $16 \mathrm{mg} / \mathrm{L}$ (normal range 0-3.5 mg/L). All the other laboratory tests for autoimmune and infectious causes of vasculopathy were negative. 3D isotropic VW-MRI showed thickening of the vessel walls of bilateral vertebral arteries and basilar artery (Add Fig 2B, D) with contrast enhancement (Add Fig 2C, E). The patient took steroids for management. On 3 months, he still reported headache, but did not complete follow-up in neuroimaging. 
2.5 Case 5区A 33-year-old male engineer presented with sudden-onset right-sided weakness, slurred speech, and memory impairment. He had cerebral infarction in the left MCA territory 1 year before. He had residual deficits, with combined aphasia, dyslexia, dysgraphia, and memory impairment. No cerebrovascular risk factors were noted. Neurological examination demonstrated central right-sided hemiparesis, with complete aphasia, dyslexia, and dysgraphia, and he displayed impaired recall and executive processing on cognitive assessment. Laboratory tests for rheumatologic disorders, autoimmune diseases, and infectious causes of vasculopathy were all negative. DWI revealed acute cerebral infarction on the left anterior cerebral artery territory (Add Fig 3B). MRA demonstrated severe stenosis or occlusion of the bilateral ICA (Add Fig 3A). He was given aspirin and clopidogrel for management. Three months later, he returned to the clinic with defective vision. Neurologic examination revealed right-sided sensory loss, homonymous hemianopia, and difficulties in naming and expression and severe memory deficits. DWI showed acute infarction in the left posterior cerebral artery territory (Add Fig 3C). 3D isotropic VW-MRI showed vessel wall thickening of the right ICA with uniform enhancement (Add Fig 3D, E). Further laboratory parameters for vasculitis all remained within normal range. The patient was ultimately diagnosed as having PACNS. Experimental treatment using methylprednisolone was performed $(1,000 \mathrm{mg} / \mathrm{d}$, halved every 3 days). At follow-up almost 3 month later, 3D isotropic VW-MRI showed resolution of stenosis (Add Fig 3F, G).

\section{Discussion And Conclusions}

PACNS is an uncommon single-organ vasculitis that is still poorly understood(9-11). PACNS could lead to various neurological manifestations, including headache, altered cognition, focal weakness, and stroke(1). The three different pathology types of PACNS are granulomatous, lymphocytic, and necrotizing vasculitis, of which granulomatous vasculitis is the most common, featuring vasculocentric mononuclear inflammation and well-formed granulomas with multinucleated giant cells(1, 12). Diagnostic criteria for PACNS were first proposed by Calabrese et al., which has been widely used for over 20 years, and consist of the following: (1) the presence of an acquired otherwise unexplained neurological or psychiatric deficit; (2) the presence of either classic angiographic or histopathologic features of angiitis within the central nervous system; and (3) no evidence of systemic vasculitis or any disorder that could cause or mimic the angiographic or pathologic features of the disease(7). Nevertheless, diagnosing PACNS can be quite challenging because of its diverse clinical features and lack of crucial laboratory tests. Most of the mimicking conditions would not benefit from steroids and immunosuppressive therapy, so the accurate diagnosis is very important. Brain biopsy is still the gold standard and should be performed whenever possible. But due to the invasive nature of biopsy, it has its limits, especially for intracranial vessels(13).

Several vasculopathies, such as reversible cerebral vasoconstriction syndrome (RCVS), atherosclerosis, moyamoya disease, and fibromuscular dysplasia, could show similar imaging features as PACNS on traditional imaging protocols like CTAIMRA or DSA, showing "beading" pattern of segmental dilation and narrowing of multiple cerebral arteries(2, 14-16). VW-MRI could directly visualize the abnormality of the vessel wall and therefore has become an important tool for evaluation. Vasculitis is usually characterized as smooth, homogeneous, concentric arterial wall thickening with enhancement, while atherosclerotic plaque usually displays nonconcentric and heterogeneous vessel wall abnormality. RCVS can show similar smooth, concentric vessel wall thickening with or without diffuse vessel stenosis. But patients with RCVS would not display vessel wall enhancement(17-20). Furthermore, in order to precisely interpret VW-MRI images, the images need to be analyzed in at least both long-axis and short-axis plane. But for 2D VW-MRI sequences, they can only be restricted to one fixed angle for one time scanning process(Add Fig 4D-F). Since the intracranial vessels can be oblique, curved, and tortuous, 2D sequences could lead to partial volume averaging effects and confound the vasculopathies(6, 20). Since the 3D VW-MRI sequences we applied are isotropic, they can be reconstructed in any angle. Additionally, 3D isotropic VW-MRI sequences with a big field of view including both the complete brain vasculature as well as the cervical arteries can supply images more efficiently, with relatively less artefacts, in relatively less time, since they are more stable against laminar flow and other artifacts(21-23). Several previous studies had illustrated that 2D VW-MRI can be a valuable approach to differentiate various vasculopathies, as well as provide more precise evaluation of vessel wall $(3-5,17,24-31)$. The application was also recommended in the "Intracranial Vessel Wall MRI: Principles and Expert Consensus Recommendations of the American Society of Neuroradiology(20)".

In this study, we present 5 cases of PACNS that including 13 affected vessels. We speculate that cervical arteries are more vulnerable to PACNS; meanwhile, due to the existence of vasorum, the interpretation of cervical artery vessel wall enhancement needs to be done cautiously, since they might be a normal phenomenon of vasa vasorum enhancement. There were 13 involved vessels in these 5 cases. With regard to vessel wall thickening and enhancement pattern, $12(12 / 13,92.3 \%)$ vessels showed circumferential or eccentric wall thickening with contrast enhancement, and only $1(1 / 13,7.69 \%)$ vessel displayed absence of vessel wall thickening or enhancement on admission, but showed progression on follow-up observation. Among the 12 vessel wall enhancements, 11 (11/12, 91.7\%) showed homogeneous enhancement pattern, $1(1 / 12,8.3 \%)$ showed eccentric enhancement. As for the degree of vessel wall enhancement, 1 $(1 / 12,8.3 \%)$ showed grade 0 intensity, $2(2 / 12,16.7 \%)$ showed grade 1 intensity, and the other 10 (10/12, 83.3\%)vessels showed grade 
2 intensity (Tab 1). Furthermore, all the 5 cases were involved of both anterior and posterior circulation, even the vasculopathy may be asymptomatic. Compared with traditional 2D VW-MRI, 3D isotropic VW-MRI could assess the whole brain and neck vasculature in one time, and apple reconstruction in any angle. It would be more convenient since PACNS can be multiple-vessel-involving.

To our knowledge, there were three articles that described follow-up features of PACNS. Pfefferkorn et al described moderate-to-strong enhancement in 4 patients with PACNS. As for follow-up, 2 patients showed persistent vessel wall enhancement on 2 months and 2 patients displayed resolution of vessel wall enhancement on 6 months, all of them were given immunosuppressive therapy(25). The second case report by Saam et al described a patient diagnosed of PACNS with strong vessel wall enhancement in multiple arteries. Follow-up imaging showed partial resolution in vessel wall enhancement on 3 months, and further substantial decrease with some persistent enhancement on 6 months(32). E.C. Obusez et al reported 13 PACNS patients with temporal patterns, the vessel wall thickening and enhancement were persistent for a median of 13.5 months in 4 patients. While in other 2 patients, there was complete resolution after a mean of 7 months(5). In our study, five patients separately took steroids, immune-suppressors, antiplatelets, and parahormone therapy, and three patients completed the imaging follow-up at 3-24 months. One patient displayed partial resolution on 3 months of steroids; one patient showed persistent vasculopathy at 24-month follow-up, the other patient (Case 1) showed gradual resolution of the anterior circulation but progression of the posterior circulation. Especially for case 1, the left vertebral artery of the patient was normal on disease onset, while saw gradual occlusion in 12 months.(Fig 1, Tab 2). The findings in our study were consistent with previous researches, reminding us of the stubborn and aggressive nature of PACNS, as well as the importance of whole brain and neck vasculature evaluation. Our case series had several deficiencies, including the absence of brain biopsy evidence and incomplete imaging follow-up. But we do explore the utility of 3D isotropic VW-MRI in PACNS.

We assert that 3D isotropic VW-MRI can evaluate the specific vasculopathy as well as the whole brain vasculature more effectively. 3D isotropic vessel wall imaging could evaluate the specific responsible vessel as well as the whole brain vasculature in one-time scan, providing detailed information in detection, diagnosis, evaluation and follow-up. Moreover, primary angiitis of the central nervous system tend to be multi-vessel involving, so the 3D isotropic vessel wall imaging could be more applicable. Thus far, the application of imaging in PACNS was qualitative. In the future, as the improvement of 7 Tesla scanning techniques, VW-MRI may achieve quantification assessment of vasculitis and provide more utility for PACNS(33).

\section{Abbreviations}

PACNS: primary angiitis of the central nervous system; CTA: computed tomography angiography; MRA: magnetic resonance angiography; DSA: digital subtraction angiography; VW-MRI: vessel wall magnetic resonance imaging; CSF: cerebrospinal fluid; CNS: central nervous system; FLAIR: fluid-attenuated inversion recovery; DWI: diffusion weighted imaging; VISTA: volume isotropic turbo spinecho acquisition; SWI: susceptibility weighted imaging; RCVS: Reversible Cerebral Vasoconstriction

\section{Declarations}

\section{Ethics approval and consent to participate}

Not applicable

\section{Consent for publication}

Written informed consents were obtained from the patients for publication of the case reports and any accompanying images. A copy of the written consents are available for review by the editor of this journal.

\section{Availability of data and material}

Not applicable

\section{Competing interests}

The authors declare that they have no competing interests.

\section{Funding}


The authors disclosed receipt of the following financial support for the research, authorship, and/or publication of this article: the National Key R\&D Program of China (Grant No. 2016YFC1301600) to Yi Yang, the Program for JLUSTIRT (2017TD-12) to Yi Yang and Shenzhen Science and Technology Innovation Commission (Grant No. JCYJ20160608153506088) to Jia Liu.

\section{Authors' contributions}

Conception and design: $\mathrm{HJ}, \mathrm{YY} 1$; acquisition of data: $Y Y 2, \mathrm{HZ}, \mathrm{FZ}, \mathrm{PN}, \mathrm{YL}, \mathrm{CW}, \mathrm{MS}, \mathrm{HJ}$; analysis and interpretation of data: YY2, HZ, ZG, FZ, PN, YL; drafting the article: YY2; revising the article critically for intellectual content: $H Z, Z G, F Z, P N, Y L, C W, M S, J L, H Q, H J, Y Y 1$; final approval of the version to be published: YY2, HZ, ZG, FZ, PN, YL, CW, MS, JL, HQ, HJ, YY1; agreement to be accountable for all aspects of the work in ensuring that questions related to the accuracy or integrity of any part of the work are appropriately investigated and resolved: YY2, HZ, ZG, FZ, PN, YL, CW, MS, JL, HQ, HJ, YY1

\section{Acknowledgements}

The authors are grateful to all the members of "Yang Lab" research team.

\section{Reference}

1. Salvarani C, Brown RD, Jr., Hunder GG. Adult primary central nervous system vasculitis. Lancet. 2012;380(9843):767-77.

2. Singhal AB. Diagnostic challenges in RCVS, PACNS, and other cerebral arteriopathies. Cephalalgia. 2011;31(10):1067-70.

3. Mossa-Basha M, Hwang WD, De Havenon A, Hippe D, Balu N, Becker KJ, et al. Multicontrast high-resolution vessel wall magnetic resonance imaging and its value in differentiating intracranial vasculopathic processes. Stroke. 2015;46(6):1567-73.

4. Mandell DM, Matouk CC, Farb RI, Krings T, Agid R, terBrugge K, et al. Vessel wall MRI to differentiate between reversible cerebral vasoconstriction syndrome and central nervous system vasculitis: preliminary results. Stroke. 2012;43(3):860-2.

5. Obusez EC, Hui F, Hajj-Ali RA, Cerejo R, Calabrese LH, Hammad T, et al. High-resolution MRI vessel wall imaging: spatial and temporal patterns of reversible cerebral vasoconstriction syndrome and central nervous system vasculitis. AJNR American journal of neuroradiology. 2014;35(8):1527-32.

6. Antiga L, Wasserman BA, Steinman DA. On the overestimation of early wall thickening at the carotid bulb by black blood MRI, with implications for coronary and vulnerable plaque imaging. Magn Reson Med. 2008;60(5):1020-8.

7. Calabrese LH, Mallek JA. Primary angiitis of the central nervous system. Report of 8 new cases, review of the literature, and proposal for diagnostic criteria. Medicine (Baltimore). 1988;67(1):20-39.

8. Qiao Y, Zeiler SR, Mirbagheri S, Leigh R, Urrutia V, Wityk R, et al. Intracranial plaque enhancement in patients with cerebrovascular events on high-spatial-resolution MR images. Radiology. 2014;271(2):534-42.

9. Gallagher KT, Shaham B, Reiff A, Tournay A, Villablanca JP, Curran J, et al. Primary angiitis of the central nervous system in children: 5 cases. The Journal of rheumatology. 2001;28(3):616-23.

10. Lanthier S. Primary angiitis of the central nervous system in children: 10 cases proven by biopsy. The Journal of rheumatology. 2002;29(7):1575-6.

11. Moharir M, Shroff M, Benseler SM. Childhood central nervous system vasculitis. Neuroimaging clinics of North America. 2013;23(2):293-308.

12. Salvarani C, Brown RD, Jr., Calamia KT, Christianson TJ, Weigand SD, Miller DV, et al. Primary central nervous system vasculitis: analysis of 101 patients. Ann Neurol. 2007;62(5):442-51.

13. Birnbaum J, Hellmann DB. Primary angiitis of the central nervous system. Archives of neurology. 2009;66(6):704-9.

14. Koopman K, Uyttenboogaart M, Luijckx GJ, De Keyser J, Vroomen PC. Pitfalls in the diagnosis of reversible cerebral vasoconstriction syndrome and primary angiitis of the central nervous system. European journal of neurology. 2007;14(10):1085-7.

15. Hajj-Ali RA, Singhal AB, Benseler S, Molloy E, Calabrese LH. Primary angiitis of the CNS. The Lancet Neurology. 2011;10(6):561-72. 
16. Xu WH, Li ML, Gao S, Ni J, Zhou LX, Yao M, et al. In vivo high-resolution MR imaging of symptomatic and asymptomatic middle cerebral artery atherosclerotic stenosis. Atherosclerosis. 2010;212(2):507-11.

17. Swartz RH, Bhuta SS, Farb RI, Agid R, Willinsky RA, Terbrugge KG, et al. Intracranial arterial wall imaging using high-resolution 3-tesla contrast-enhanced MRI. Neurology. 2009;72(7):627-34.

18. Yuan C, Petty C, O'Brien KD, Hatsukami TS, Eary JF, Brown BG. In vitro and in situ magnetic resonance imaging signal features of atherosclerotic plaque-associated lipids. Arteriosclerosis, thrombosis, and vascular biology. 1997;17(8):1496-503.

19. Han JS, Mandell DM, Poublanc J, Mardimae A, Slessarev M, Jaigobin C, et al. BOLD-MRI cerebrovascular reactivity findings in cocaine-induced cerebral vasculitis. Nature clinical practice Neurology. 2008;4(11):628-32.

20. Mandell DM, Mossa-Basha M, Qiao Y, Hess CP, Hui F, Matouk C, et al. Intracranial Vessel Wall MRI: Principles and Expert Consensus Recommendations of the American Society of Neuroradiology. AJNR American journal of neuroradiology. 2017;38(2):218-29.

21. Alexander AL, Buswell HR, Sun Y, Chapman BE, Tsuruda JS, Parker DL. Intracranial black-blood MR angiography with high-resolution 3D fast spin echo. Magnetic resonance in medicine. 1998;40(2):298-310.

22. Qiao Y, Steinman DA, Qin Q, Etesami M, Schar M, Astor BC, et al. Intracranial arterial wall imaging using three-dimensional high isotropic resolution black blood MRI at 3.0 Tesla. Journal of magnetic resonance imaging : JMRI. 2011;34(1):22-30.

23. Zhang L, Zhang N, Wu J, Zhang L, Huang Y, Liu X, et al. High resolution three dimensional intracranial arterial wall imaging at 3 T using T1 weighted SPACE. Magnetic resonance imaging. 2015;33(9):1026-34.

24. Mossa-Basha M, de Havenon A, Becker KJ, Hallam DK, Levitt MR, Cohen WA, et al. Added Value of Vessel Wall Magnetic Resonance Imaging in the Differentiation of Moyamoya Vasculopathies in a Non-Asian Cohort. Stroke. 2016;47(7):1782-8.

25. Pfefferkorn T, Linn J, Habs M, Opherk C, Cyran C, Ottomeyer C, et al. Black blood MRI in suspected large artery primary angiitis of the central nervous system. Journal of neuroimaging : official journal of the American Society of Neuroimaging. 2013;23(3):379-83.

26. Cheng-Ching E, Jones S, Hui FK, Man S, Gilden D, Bhimraj A, et al. High-resolution MRI vessel wall imaging in varicella zoster virus vasculopathy. Journal of the neurological sciences. 2015;351(1-2):168-73.

27. Niu PP, Yu Y, Zhou HW, Liu Y, Luo Y, Guo ZN, et al. Vessel wall differences between middle cerebral artery and basilar artery plaques on magnetic resonance imaging. Sci Rep. 2016;6:38534.

28. Niu PP, Yu Y, Guo ZN, Jin H, Liu Y, Zhou HW, et al. Diagnosis of non-acute cerebral venous thrombosis with 3D T1-weighted black blood sequence at 3T. J Neurol Sci. 2016;367:46-50.

29. Zhang FL, Liu Y, Xing YQ, Yang Y. Diagnosis of cervical artery dissection using 3-T magnetic resonance imaging. JAMA Neurol. 2015;72(5):600-1.

30. Luo Y, Guo ZN, Niu PP, Liu Y, Zhou HW, Jin H, et al. 3D T1-weighted black blood sequence at 3.0 Tesla for the diagnosis of cervical artery dissection. Stroke Vasc Neurol. 2016;1(3):140-6.

31. Zhang FL, Guo ZN, Liu Y, Luo Y, Yang Y. Dissection extending from extra- to intracranial arteries: A case report of progressive ischemic stroke. Medicine (Baltimore). 2017;96(21):e6980.

32. Saam T, Habs M, Pollatos O, Cyran C, Pfefferkorn T, Dichgans M, et al. High-resolution black-blood contrast-enhanced T1 weighted images for the diagnosis and follow-up of intracranial arteritis. The British journal of radiology. 2010;83(993):e182-4.

33. Goll C, Thormann M, Hofmuller W, Friebe B, Behrens-Baumann W, Bley TA, et al. Feasibility study: 7 T MRI in giant cell arteritis. Graefe's archive for clinical and experimental ophthalmology = Albrecht von Graefes Archiv fur klinische und experimentelle Ophthalmologie. 2016;254(6):1111-6.

\section{Tables}

Table 1: Vasculopathy Patterns

Page $7 / 12$ 


\begin{tabular}{|c|c|c|}
\hline & Vasculopathy $(n=13)$ & \\
\hline \multirow{5}{*}{ Location } & ICA & $3 \llbracket 23.1 \rrbracket \rrbracket$ \\
\hline & VA & $4 \llbracket 30.8 \llbracket \rrbracket$ \\
\hline & BA & 2ه15.4ه囚 \\
\hline & MCA & $2 \varangle 15.4 \llbracket \rrbracket$ \\
\hline & PCA & $2 \varangle 15.4 \rrbracket \bigotimes$ \\
\hline \multirow{4}{*}{ Degree of Stenosis* } & Absence & 2ه15.4区区 \\
\hline & Mild & $1 \otimes 7.7 \otimes \square$ \\
\hline & Moderate & $2 \varangle 15.4 \llbracket \rrbracket$ \\
\hline & Severe or Occlusion & $8 \llbracket 61.5 \rrbracket \square$ \\
\hline \multirow[t]{3}{*}{ Wall thickening } & Eccentric & $187.7 \otimes \square$ \\
\hline & Circumferential & $11 \llbracket 84.6 \rrbracket \square$ \\
\hline & Absent & 1ब7.7欧 \\
\hline \multirow[t]{2}{*}{ CE } & Present & 12ष92.3ه \\
\hline & Absent & 1ه7.7怄 \\
\hline \multirow[t]{3}{*}{ CE Intensity\# } & Grade 0 & $187.7 \otimes \square$ \\
\hline & Grade 1 & $2 \rrbracket 15.4 \llbracket \rrbracket$ \\
\hline & Grade 2 & $10 \otimes 76.9 \otimes \square$ \\
\hline \multirow[t]{3}{*}{ CE Pattern } & Absent & $187.7 \otimes \square$ \\
\hline & Heterogeneous & 187.7时 \\
\hline & Homogeneous & $11 \rrbracket 84.6 \varangle \square$ \\
\hline
\end{tabular}

Abbreviations:

ICA: Internal Carotid Artery; VA: Vertebral Artery; BA: Basilar Artery;MCA: Middle Cerebral Artery; PCA: Posterior Cerebral Artery; CE:

Contrast Enhancement; *Degree of Stenosis was assessed by MRA, graded the vessel narrowing as mild ( $\$ 50 \%)$, moderate (50\%-79\%), severe or occlusion ( $\triangle 80 \mathrm{Q})$; \#CE Intensity was assessed by protocol demonstrated in the Materials and Methods section.

Table 2: Clinical Characteristics and Prognosis Features 


\begin{tabular}{|c|c|c|c|c|c|c|c|c|c|c|}
\hline Case & Age & Sex & $\begin{array}{l}\text { Onset } \\
\text { Clinical } \\
\text { Disease }\end{array}$ & $\begin{array}{l}\text { Vessels } \\
\text { Involved }\end{array}$ & MRA & $\begin{array}{l}\text { Interval } \\
\text { Between } \\
\text { Onset } \\
\text { and VW- } \\
\text { MRI } \\
\text { 『month }\end{array}$ & $\begin{array}{l}\text { Wall } \\
\text { Thickening } \\
\text { and CE }\end{array}$ & Management & $\begin{array}{l}\text { Follow- } \\
\text { up } \\
\text { Features }\end{array}$ & \\
\hline & & & & & & & & & $\begin{array}{l}\text { Length } \\
\text { (month) }\end{array}$ & Outcome \\
\hline \multirow[t]{4}{*}{1} & \multirow[t]{4}{*}{21} & M & $\begin{array}{l}\text { Ischemic } \\
\text { Infarction }\end{array}$ & $\begin{array}{l}\text { RICA } \\
\text { \&RMCA } \\
\text { \&LVA }\end{array}$ & $\begin{array}{l}\text { Diffuse } \\
\text { Stenosis } \\
\text { to } \\
\text { Occlusion }\end{array}$ & 1 & + & $\begin{array}{l}\text { Steroids } \\
\text { CYC }\end{array}$ & 1 & $\begin{array}{l}\text { Resolution } \\
\text { on RMCA } \\
\text { Persistence } \\
\text { on LVA }\end{array}$ \\
\hline & & & & & & & & & 3 & $\begin{array}{l}\text { Resolution } \\
\text { on RMCA } \\
\text { Persistence } \\
\text { on LVA }\end{array}$ \\
\hline & & & & & & & & & 6 & $\begin{array}{l}\text { Resolution } \\
\text { on RMCA } \\
\text { Persistence } \\
\text { on LVA }\end{array}$ \\
\hline & & & & & & & & & 12 & $\begin{array}{l}\text { Resolution } \\
\text { on RMCA } \\
\text { Persistence } \\
\text { on LVA }\end{array}$ \\
\hline 2 & 26 & $M$ & $\begin{array}{l}\text { Ischemic } \\
\text { Infarction }\end{array}$ & $\begin{array}{l}\text { RVA\& BA } \\
\& \text { LPCA }\end{array}$ & $\begin{array}{l}\text { Diffuse } \\
\text { Moderate } \\
\text { to Severe } \\
\text { Stenosis }\end{array}$ & 12 & + & Steroids & 24 & $\begin{array}{l}\text { Persistence } \\
\text { on RVA, BA } \\
\text { and LPCA }\end{array}$ \\
\hline 3 & 35 & $M$ & $\begin{array}{l}\text { Ischemic } \\
\text { Infarction } \\
\text { \&Headache }\end{array}$ & $\begin{array}{l}\text { RICA } \\
\text { \&RMCA }\end{array}$ & Occlusion & 1 & + & Steroids & I & I \\
\hline 4 & 49 & $M$ & Headache & $\begin{array}{l}\text { RVA\& LVA } \\
\text { \&BA\&LPCA }\end{array}$ & $\begin{array}{l}\text { Local } \\
\text { Moderate } \\
\text { Stenosis }\end{array}$ & 24 & + & Steroids & / & / \\
\hline 5 & 33 & $M$ & $\begin{array}{l}\text { Ischemic } \\
\text { Infarction }\end{array}$ & RICA & $\begin{array}{l}\text { Diffuse } \\
\text { Stenosis } \\
\text { to } \\
\text { Occlusion }\end{array}$ & 15 & + & Steroids & 3 & Resolution \\
\hline
\end{tabular}

\section{Abbreviations:}

M: Male; CE: Contrast Enhancement; CYC: Cyclophosphamide; RICA: Right Internal Carotid Artery; RMCA: Right Middle Cerebral Artery; LVA: Left Vertebral Artery; BA: Basilar Artery; LICA: Left Internal Carotid Artery; LMCA: Right Middle Cerebral Artery; RVA: Right Vertebral artery; LPCA: Left Posterior Cerebral Artery;

\section{Figures}



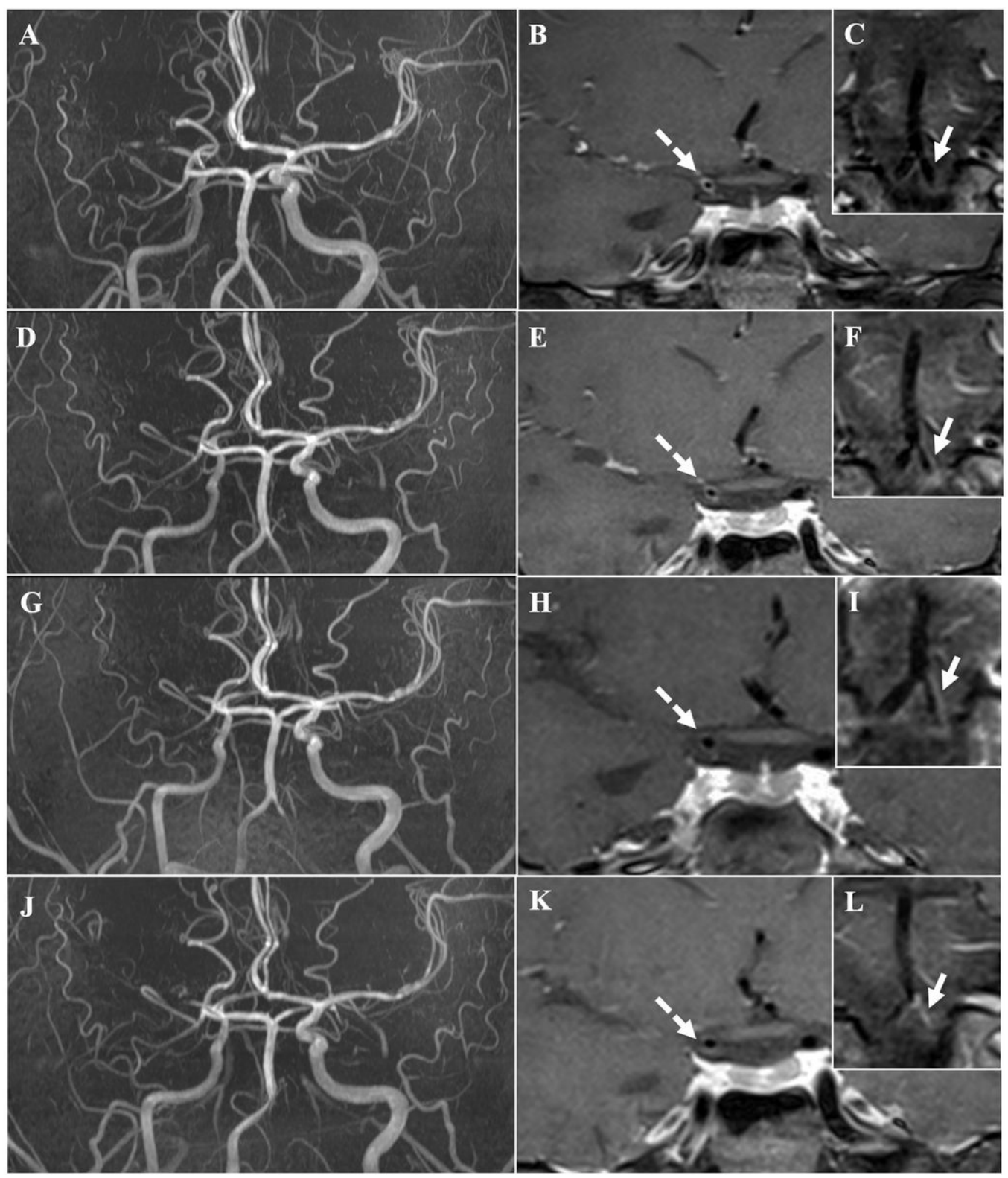

\section{Figure 1}

Case 1: (A): MRA shows diffuse stenosis to occlusion of the right ICA and right MCA; (B): 3D VW-MRI shows uniform thickening of the vessel wall of terminal right ICA with contrast enhancement; (C): 3D VW-MRI shows no obvious abnormality in the left vertebral artery; (D): Imaging follow-up at 3 months, MRA shows persistent stenosis to occlusion of the right ICA and right MCA, along with newly revealed vessel wall stenosis of the left vertebral artery; $(E)$ : 3D VW-MRI shows persistent vasculopathy of the vessel wall of the terminal right ICA, but the intensity of contrast enhancement declined; (F): 3D VW-MRI shows thickened vessel wall of the left vertebral artery, with mild contrast enhancement; (G): Imaging follow-up at 6 months, MRA shows persistent stenosis to occlusion of the right ICA and right MCA, while the left vertebral artery is nearly occluded. (H): 3D VW-MRI shows persistent vasculopathy of the vessel wall of the terminal right ICA, but the intensity of contrast declined; (I): 3D VW-MRI shows progressively thickening vessel wall of the left vertebral artery, and the intensity of contrast enhancement increased; $(\mathrm{J})$ : Imaging follow-up at 12 months, MRA shows persistent stenosis to occlusion of the right ICA and right MCA, while the left vertebral artery is occluded; (K): 3D VW-MRI shows persistent vasculopathy of the vessel wall of the terminal right ICA; (L): 3D VW-MRI shows progressively thickening vessel wall of the left vertebral artery, and the intensity of contrast enhancement continues to increase. 


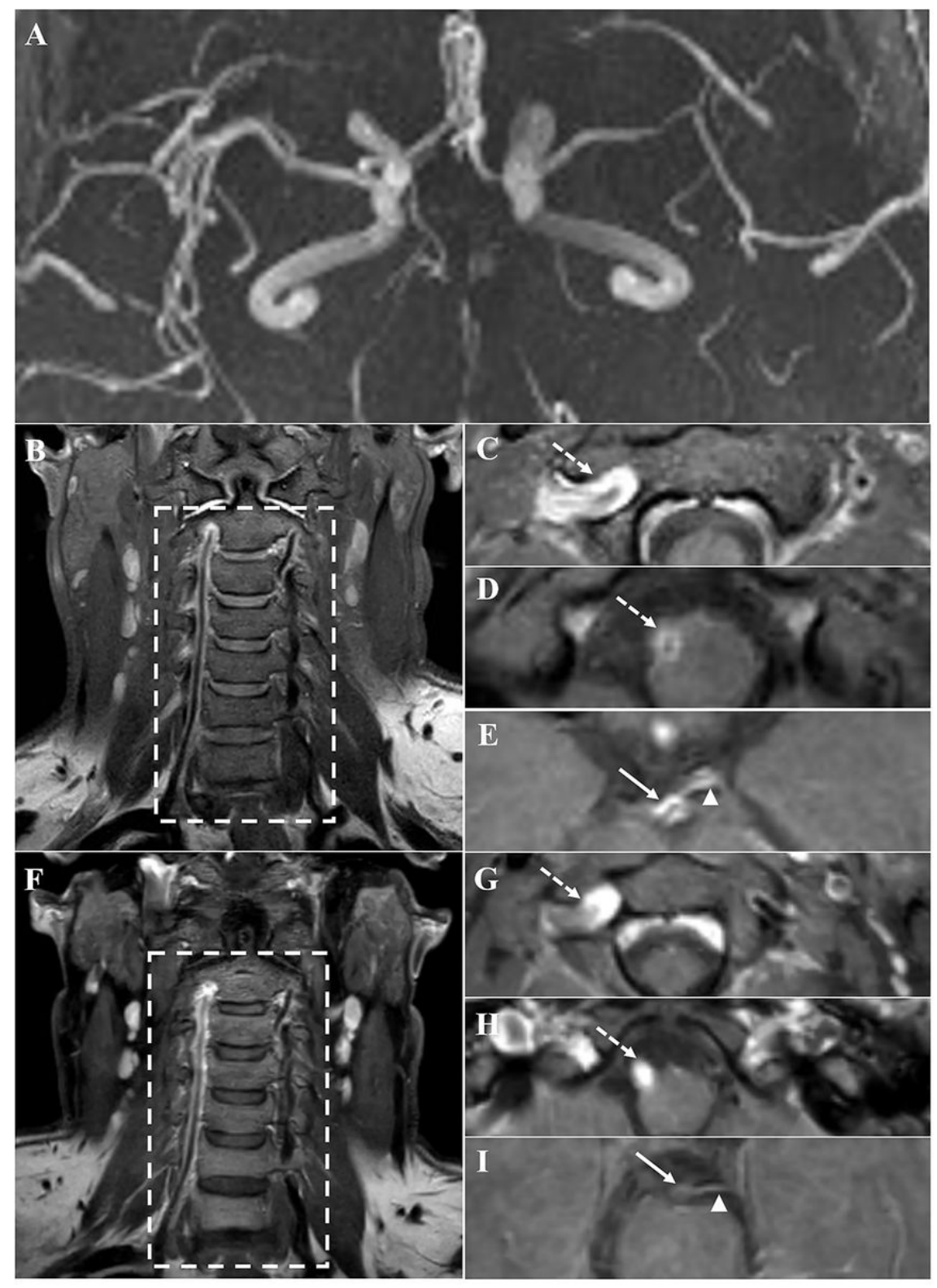

\section{Figure 2}

Case 2: (A): MRA indicates severe stenosis of the left MCA and poor visualization of the basilar artery, bilateral vertebral artery, and posterior cerebral artery; (B): 3D VW-MRI shows uniform vessel wall thickening of the right vertebral artery, the basilar artery, and the left posterior cerebral artery; (C): 3D VW-MRI shows uniform vessel wall thickening of the right ICA with contrast enhancement; (D): 3D VWMRI shows uniform vessel wall thickening of the right vertebral artery with contrast enhancement; (E): 3D VW-MRI shows uniform vessel wall thickening of the basilar artery and left posterior cerebral artery, both with contrast enhancement; (F): Imaging follow-up at 1-year, 3D VW-MRI shows persistent vasculopathy of the right vertebral artery, the basilar artery, and the left posterior cerebral artery; $(G, H, I): 3 D$ VW-MRI shows uniform vessel wall thickening of the right ICA, right vertebral, and left posterior cerebral artery.

\section{Supplementary Files}

This is a list of supplementary files associated with this preprint. Click to download.

- AdditionalFigure2.jpg

- AdditionalFigure4.jpg

- Timeline.pdf

- CAREchecklistEnglish2013.pdf

- AdditionalFigure1.jpg 
- AdditionalFigure3.jpg

Page $12 / 12$ 